\author{
WILLIAM POOLE*
}

Special Studies Section, Division of

Research and Statistics, Board of

Governors of the Federal Reserve System

\title{
The Role of Interest Rates and Inflation in the Consumption Function
}

Most OF THE ANALYSIS of the effects of interest rate changes on consumption has been concerned with (1) the relative importance of income and substitution effects in determining how households will allocate their resources over time, and (2) the substitution effect at a moment of time determining the demands for durable versus nondurable consumption goods. But two other types of interest rate effects on consumption-effects that have received little attention in the literature-may be of some importance and are the subject of this report. The rate of inflation enters the analysis because of the wedge it drives between the nominal and real rates of interest.

One of the effects to be considered is a consequence of the fact that the real rate of interest helps determine the services yielded by the stock of consumer durables. Following a common practice in econometric work on consumption, the services of durables are included in consumption and purchases of consumer durables are excluded. Services of durables must also be added to disposable income. Since the value of such services cannot be ascertained from market transactions, it must be imputed. The stock of consumer durables is first estimated, and then multiplied by a depreciation rate and a net rate of return to obtain the gross yield on the stock. Since

* Bonnie Garrett handled the computer work. The author is solely responsible for the views expressed and any errors of analysis. 
consumers can be expected to equate the net rate of return on durables to the interest rate on financial assets, the interest rate enters into the determination of the yield on consumer durables.

Another neglected factor in the study of consumption behavior is the treatment of the gross interest income of households. In calculating real income during an inflationary period, households should take account of the depreciation in the real value of their fixed income assets. Since an inflation premium finds its way into nominal interest rates precisely because of this depreciation, and compensates for it, consumers can allow for the depreciation by saving in entirety that part of their gross interest income that represents the inflation premium. A theoretically correct definition of "income" should either exclude that part of interest income that is an inflation premium, or, equivalently, include the anticipated part of the capital losses in real terms on the household's portfolio of fixed income assets.

Both of these issues become important whenever nominal and real rates of interest diverge, that is, whenever inflationary or deflationary anticipations develop. To study these issues I have used the consumption function of the SSRC-MIT-Penn (SMP) model. This function will be called the "standard" function and will serve as a benchmark in making comparisons with formulations suggested by the analysis. An alternative formulation will be examined after an outline of the current formulation of the SMP consumption function. ${ }^{1}$

\section{The SMP Consumption Function}

Real consumption, CON, is defined by

$$
C O N=E C N+Y C D+W C D,
$$

where $E C N$ is consumer expenditures on nondurable goods and services, and $Y C D$ and $W C D$ are, respectively, the net yield on and depreciation of the stock of consumer durable goods. These variables are all in real terms (1958 dollars). The quarterly equations for $Y C D$ and $W C D$ are

$$
Y C D=0.0379\left(0.125 E C D+K C D_{-1}\right)
$$

1. The SMP consumption function is a modified version of the life cycle consumption model. See Albert Ando and Franco Modigliani, "The 'Life Cycle' Hypothesis of Saving: Aggregate Implications and Tests," American Economic Review, Vol. 53 (March 1963), pp. 55-84. 
and

$$
\begin{aligned}
W C D & =0.225 K C D_{-1}+0.45(0.125 E C D) \\
& =0.225\left(0.25 E C D+K C D_{-1}\right),
\end{aligned}
$$

where $E C D$ is expenditures on consumer durables at annual rates and $K C D$ is the stock of consumer durables at the end of the quarter.

The assumptions underlying equation (2) are easily explained. Since $E C D$ is measured at annual rates, it is necessary to divide it by 4.0 to obtain a quarterly rate. Thus, in the absence of depreciation, $K C D=0.25 E C D+$ $K C D_{-1}$. However, the amount of services yielded by consumer durables over the quarter depends on the integral of the instantaneous rate of yield on the level of the stock. This amount may be approximated by applying the rate of yield to the average level of the stock over the quarter, which is approximately $1 / 2\left(K C D+K C D_{-1}\right)=0.125 E C D+K C D_{-1}$. The rate of yield applied to this stock is 3.79 percent. The reason for selecting this yield will be explained below.

Equation (3) may be derived in a similar fashion. The stock of consumer durables is assumed to depreciate at a rate of 22.5 percent per annum, except for the first quarter, during which the rate of depreciation is assumed to be 45 percent.

The equations for nominal magnitudes are as follows:

$$
\begin{gathered}
E C D \$=P C D(E C D) \\
K C D \$=P C D(K C D) \\
Y C D \$=0.01 R C B(0.125 E C D \$+K C D \$-1) \\
W C D \$=0.225(0.25 E C D \$+K C D \$-1)=P C D(W C D) \\
C O N \$=E C N \$+Y C D \$+W C D \$ \\
P C O N=\frac{C O N \$}{C O N} .
\end{gathered}
$$

In these equations variable names ending with a dollar sign are the currentdollar equivalents of the real variables. In equations (4), (5), and (7) currentdollar variables are obtained from real variables by multiplying by $P C D$, the price index for consumer durable goods. $R C B$ is the corporate bond rate, and $P C O N$ is the consumption deflator.

One difficulty with the standard model arises in equation (6). The nomi- 
nal interest rate ought to be replaced with the real interest rate, because the present value of the stream of services yielded by a durable good can be calculated either by discounting the future nominal stream of services by the nominal interest rate, or by discounting the future real stream of services by the real interest rate. The two formulations are equivalent since the difference between the nominal and real services is the accumulated amount of anticipated inflation, and the difference between the nominal and real interest rates is the anticipated rate of inflation. The procedure followed in equation (6) is equivalent to discounting the (assumed constant) future stream of real services by the nominal interest rate. Correcting equation (6), therefore, requires the substitution of a real rate of interest for $R C B$.

Equation (2), determining $Y C D$, employs a constant yield of 3.79 percent, a result stemming from the way in which price indexes are calculated. This result is derived as follows: In equilibrium,

$$
S_{t}=\left(r_{t}+d_{t}\right) P C D_{t},
$$

where $S_{t}$ is the current-dollar rental rate for one unit of consumer durables, $d_{t}$ is the depreciation rate, and $r_{t}$ is the real rate of interest. An index, $I S$, of the rental price of consumer durables may then be defined as

$$
I S_{t}=\frac{S_{t}}{S_{0}}=\frac{\left(r_{t}+d_{t}\right) P C D_{t}}{\left(r_{0}+d_{0}\right) P C D_{0}} .
$$

It is convenient to assume that the base year for the price index $P C D$ is year $t=0$ so that $P C D_{0}=1$.

In terms of the model's notation, $S=(Y C D \$+W C D \$) / K C D$. If one ignores the minor complication raised by the assumption of a more rapid depreciation rate in the first quarter and assumes a constant depreciation rate, deflating the sum of (6) and (7) by the index defined in (11) yields the sum of (2) and (3), where 0.0379 is the value of $R C B$ for 1958 , the base year for the price indexes.

Once the consumption variable is defined, the analysis can move on to the consumption function itself. Real consumption, $C O N$, is a function of real disposable income, $Y D$, and of real household net worth, $V C N$. Real disposable income and real net worth are obtained by deflating the corresponding current-dollar magnitudes by PCON.

With all items in current-dollar terms, the model's disposable income, $Y D$ \$, equals: (1) personal income; plus (2) the gross yield on the stock of consumer durables, $Y C D \$+W C D \$$; less (3) federal, state, and local 
personal income tax liabilities; less (4) federal estate and gift taxes; less (5) interest paid by consumers.

The household net worth variable, $V C N \$$, involves a number of separate items, many of which are subject to substantial measurement problems. The attempt is to measure the market value of household net worth. Basically, the variable includes the net financial assets plus tangible assets of households and of noncorporate business, both farm and nonfarm. Tangible assets include the value of (1) the inventories of noncorporate businesses; (2) the stock of consumer durables and of noncorporate business plant and equipment; and (3) farm land and structures, nonfarm residential land and structures (excluding nonfarm corporate residential structures), and nonfarm nonresidential land. Most of the cyclical fluctuation in VCN\$ is caused by stock market fluctuations.

The consumption function is estimated using real per capita magnitudes. A twelve-quarter distributed lag is used for disposable income, and a fourquarter distributed lag for household net worth. The distributed lags are constrained to lie on a second degree polynomial and the intercept to equal zero. Estimation is by ordinary least squares using a rho transformation to eliminate serial correlation of residuals. After the coefficients, the $R^{2}$, the standard error of estimate, and the Durbin-Watson statistic have been estimated, the post-estimation predictions are calculated with rho set equal to zero. The estimation and prediction periods are 1954:1 through 1967:4 and 1968:1 through 1971:4, respectively.

The regression statistics and post-estimation performance of the standard consumption equation are shown in the column labeled "Standard equation" in Table 1. Only the sums of the lag coefficients on disposable income and net worth have been reported rather than all of the individual coefficients. The standard equation has performed reasonably well in the period since estimation, with a maximum error of $\$ 32$ per capita (in the aggregate, about $\$ 6.4$ billion in 1958 dollars, or about $\$ 7.7$ billion in current dollars).

The post-estimation performance of the standard equation is especially interesting in the light of recent discussions suggesting that the saving ratio has been abnormally high in 1970 and 1971 . Here, the saving ratio was actually lower from 1969:4 through 1971:2 than predicted by the standard equation. This result is partly a function of different definitions of consumption: The saving ratio alleged to be abnormally high includes outlays for consumer durables in the definition of consumption, while the model's CON variable includes only the current services of consumer durables. 
Even more important, the relatively low rate of consumption predicted by the standard equation for the 1970-71 period reflects weakness in the wealth variable. Recent experience, therefore, tends to support the inclusion of the wealth variable in the consumption function.

\section{Table 1. Consumption Functions for the SMP Model ${ }^{\mathrm{a}}$}

\begin{tabular}{|c|c|c|c|}
\hline $\begin{array}{l}\text { Regression item, } \\
\text { summary statistic, and } \\
\text { year and quarter }\end{array}$ & $\begin{array}{l}\text { Standard } \\
\text { equation }\end{array}$ & $\begin{array}{c}\text { Corrected } \\
\text { equation }\end{array}$ & $\begin{array}{c}\text { Alternative } \\
\text { equation }\end{array}$ \\
\hline & \multicolumn{3}{|c|}{ Regression results } \\
\hline Sum of coefficients of $Y D^{\mathrm{b}}$ & $\begin{array}{c}0.671 \\
(20.8)\end{array}$ & $\begin{array}{c}0.703 \\
(16.9)\end{array}$ & $\begin{array}{c}0.702 \\
(27.1)\end{array}$ \\
\hline Sum of coefficients of $V C N^{\mathrm{e}}$ & $\begin{array}{l}0.053 \\
(7.8)\end{array}$ & $\begin{array}{l}0.046 \\
(5.3)\end{array}$ & $\begin{array}{l}0.047 \\
(8.6)\end{array}$ \\
\hline Coefficient of YPREM ${ }^{\mathrm{d}}$ & $\ldots$ & $\ldots$ & $\begin{array}{l}-0.539 \\
(-4.0)\end{array}$ \\
\hline \multicolumn{4}{|l|}{ Summary statistics } \\
\hline$R^{2}$ & 0.997 & 0.996 & 0.997 \\
\hline Standard error of estimate & 9.2 & 10.7 & 8.7 \\
\hline Rho & 0.615 & 0.720 & 0.557 \\
\hline Durbin-Watson statistic & 0.75 & 0.56 & 0.77 \\
\hline & \multicolumn{3}{|c|}{ Residuals (1958 dollars per capita)e } \\
\hline Year and quarter & & & \\
\hline 1968:1 & -14 & -17 & -3 \\
\hline 1968:2 & -20 & -24 & -8 \\
\hline $1968: 3$ & -11 & -14 & 4 \\
\hline 1968:4 & -18 & -21 & 3 \\
\hline 1969:1 & -14 & -17 & 7 \\
\hline $1969: 2$ & -8 & -12 & 14 \\
\hline $1969: 3$ & -1 & -6 & 20 \\
\hline $1969: 4$ & 8 & 1 & 29 \\
\hline 1970:1 & 28 & 19 & 47 \\
\hline 1970:2 & 30 & 18 & 46 \\
\hline $1970: 3$ & 32 & 18 & 46 \\
\hline $1970: 4$ & 30 & 16 & 46 \\
\hline 1971:1 & 17 & 1 & 34 \\
\hline $1971: 2$ & 6 & -9 & 24 \\
\hline $1971: 3$ & -4 & -19 & 10 \\
\hline $1971: 4$ & -5 & -16 & 5 \\
\hline
\end{tabular}

Source: Derived by author; see text for discussion of equations.

a. The dependent variable is real per capita consumption (in 1958 dollars). The estimation period is $1954: 1-1967: 4$. The numbers in parentheses are $t$ ratios.

b. Sum of twelve-quarter Almon lag coefficients on real disposable income.

c. Sum of four-quarter Almon lag coefficients on household net worth.

d. Coefficient on inflation premium income, discussed in the next section.

e. Actual minus predicted. 
It appears, however, that the predictive performance of the standard equation was improved by the mistake of using the nominal rather than the real interest rate in this determination of $Y C D \$$. This error does not affect $Y C D$ (nor, therefore, $C O N$ ) but it does affect real disposable income, $Y D$. Other things equal, the higher $R C B$ is, the higher $Y C D \$$ is and therefore the higher CON\$ and $Y D \$$ are. But $C O N$ is unaffected by a higher $R C B$, and so $P C O N$ is higher because of the higher CON\$. It turns out that the magnitudes are such that a higher $R C B$ produces a lower $Y D(=$ $Y D \$ / P C O N)$. Thus, when $R C B$ rises relative to the real rate of interest, the standard SMP consumption equation uses a lower estimate of $Y D$ than does the corrected equation, which substitutes an estimate of the real rate of interest for $R C B$.

The regression statistics and post-estimate residuals for the corrected equation appear in Table 1 in the column headed "Corrected equation." The real rate of interest used in this equation is $R C B$ less a nineteen-quarter distributed lag on the percentage change in $P C D$. The distributed lag uses exponentially declining weights: $w_{k}=0.95^{k}(0.05) /\left(1-0.95^{20}\right)$.

Table 1 shows that the corrected equation has a slightly worse fit during the estimation period, but perhaps a slightly better fit over the post-estimation period as a whole. Both equations overpredict from 1968:1 through $1969: 3$, and then underpredict through $1971: 1$ or $1971: 2$, after which they again overpredict.

\section{An Alternative SMP Consumption Function}

The better performance of the standard equation implies that the ratio of $R C B$ to the real rate of interest has explanatory value. One hypothesis about this variable involves the role of the interest income component of personal income. As inflationary expectations develop, nominal interest rates rise, reflecting the erosion through inflation of the real value of fixed-dollar assets. In an ongoing inflation, bond holders must reinvest the inflation premium portion of interest income to maintain the real value of their bond portfolios. If they do, a consumption function that fails to take separate account of interest income will tend to overpredict consumption during inflationary periods, and to underpredict consumption during periods of decelerating inflation.

The hypothesis outlined above applies in reverse to household interest expenditures. To the extent that these expenditures are boosted by inflation- 
induced increases in nominal interest rates, real interest expenditures are below nominal interest expenditures. Therefore, in testing the hypothesis, the appropriate variable is the difference between interest income and interest expenditures, or net interest income.

Under the assumption that net interest income equals $R C B$ times net fixed-income assets, the inflation premium portion is $Q / R C B$ times net interest income, where $Q$ is the expected rate of inflation. Dividing this variable by $P C O N$ and by population gives per capita "inflation premium income" in 1958 dollars. This variable is called YPREM, and it is entered into the consumption equation separately.

In constructing YPREM it is necessary to calculate $Q$. The usual procedure was followed, making $Q$ depend on a distributed lag of past price changes. In this case, $P C O N$ was the logical price index. After experiments with several lag structures, the best results seemed to be obtained with a seven-quarter distributed lag on the rate of change of PCON. Exponentially declining weights- $w_{k}=0.95^{k}(0.05) /\left(1-0.95^{8}\right)$-were used. The variable $Q$ was then defined to equal this distributed lag minus 1.5 percent under the assumption that $P C O N$ has an inflationary bias of about 1.5 percent per annum.

The results of introducing the YPREM variable into the consumption function are shown in the "Alternative equation" column of Table 1. This addition improves the performance of the consumption function slightly during the estimation period. The size of the YPREM variable is a little below what would be expected if households saved the full after-tax amount of interest income arising from the inflation premium. Since the variable is $Q / R C B$ times the net interest component of personal income, no allowance has been made for personal income taxes. The YPREM coefficient of about 0.5 , when compared with the $Y D$ coefficient of about 0.7 , implies a tax rate of about 28 percent. However, over 20 percent of household interest income is imputed from the interest income received by financial intermediaries and no income tax is paid on imputed interest income. Thus, the YPREM coefficient appears to be somewhat below the level predicted by the argument regarding interest premium income.

\section{Significance of Findings}

As can be seen from Table 1, the alternative equation underpredicts consumption over most of the 1968-71 period. That is, consumption was 
stronger over this period than would have been expected from the 1954-67 experience as described by the alternative equation. Because of the inherent difficulties of measuring the expected rate of inflation by a distributed lag on past inflation, this finding must be considered tentative. But if the basic argument underlying the alternative equation is correct and consumption returns to the track predicted by that equation, it will remain below the level predicted by the corrected equation as long as households continue to expect inflation.

While these findings appear to suggest that the rate of inflation plays a role in reducing consumption, putting the point this way may be misleading. If the argument is correct, consumption is not actually reduced by inflation; rather, measured disposable income is artificially inflated as nominal interest rates reflect expected inflation. Households, recognizing that inflation is eroding the real value of their fixed-income assets, do not include all of the interest income that represents merely an inflation premium in their measure of disposable income.

The results are surely open to other interpretations. The net interest income component of personal income is dominated by trend. The $Q / R C B$ variable performs as well as the YPREM variable. The findings are consistent, therefore, with the hypothesis that inflation has a depressing psychological impact on consumption.

Whatever the correct interpretation, further attention should be given to the definitions of income and consumption during an inflationary period. These definitions are affected by the treatment of the yield on the stock of consumer durables. Income is also affected by the treatment of anticipated real capital gains and losses. Anticipations of capital gains and losses on equities and real assets may or may not be affected by inflation, but there can be no doubt that anticipations of gains and losses on fixed-dollar assets are affected by prolonged inflation. It appears that understanding inflationary periods presents problems not only because inflation affects economic behavior but also because inflation affects economic data. 


\section{Discussion}

Both Franco Modigliani and Robert Hall felt that the problem Poole confronted in his paper had broad implications for concepts of income and saving. Correcting the imputed services of durables and recorded interest income for inflation constituted only a small part of the solution. Modigliani argued that a full correction for inflation would alter the entire concept of saving; it would mark down not only interest income but also that part of increased holdings of financial assets that merely preserved the real value of total wealth. Hall suggested that the theory underlying Poole's report pointed to wage income and wealth as the two main determinants of consumption. If the theory were consistently applied throughout, the question about the treatment of interest income would never arise because no property income would be included in the income concept relevant to the consumption decision. In a sense, Hall viewed the report as an attempt to remove a little piece of a big mistake.

William Brainard suggested that the interest rate effects on the value of business debt should, conceptually, be treated differently from those on government debt. A decline in the real value of corporate bonds due to an increased inflation premium is, in principle, offset by an increase in the real value of equities. Some household has to be better off when any bondholder is made worse off as a result of inflation. On the other hand, in the case of government debt, no compensating change takes place within the household sector.

Hendrik Houthakker was concerned that the estimation of services yielded by consumer durables introduces another large imputation into the concept of consumption. Although he had long favored such a treatment, he had recently changed his mind, precisely because of the great difficulty of estimating these services. Indeed, Houthakker felt that investigators of consumption probably should move in the opposite direction and eliminate the large imputations now present in the national accounts measures of consumer expenditures and disposable income. In particular, he was troubled by the imputation for rent from owner-occupied dwellings, and that for interest on bank deposits. 